\title{
Antimicrobial stewardship in ICUs during the COVID-19 pandemic: back to the 90s?
}

\author{
Jan J. De Waele ${ }^{1 *}\left(\mathbb{B}\right.$, Lennie Derde 2,3 and Matteo Bassetti ${ }^{4}$ (B)
}

(0) 2020 Springer-Verlag GmbH Germany, part of Springer Nature

SARS-CoV-2 infection has arguably been one of the most significant challenges of health care systems around the world in over a century. The coronavirus disease 2019 (COVID-19) lead to a massive increase in demand for acute care beds in many countries [1]. Here, we focus on one of the unintended side effects of the surge in COVID19 patients in the intensive care unit (ICU).

Under these circumstances, it became challenging to uphold basic principles in patient management. During the pandemic, the goals of antimicrobial stewardship programs (ASP) remain unchanged. First, limiting antimicrobial exposure to prevent antimicrobial resistance in ventilated patients with prolonged ICU stay is highly relevant in the patient admitted with COVID-19. Second, avoiding toxicity is a particular concern, as many of the antivirals and antibiotics can have severe side effects and interactions. Finally, given the high mortality, improving the outcome of the patient with COVID-19 is central.

Remarkably, as the pandemic spread, we have been ignoring many of the antimicrobial stewardship (AMS) strategies that were developed and implemented in the past decade. Although there was no evidence that bacterial superinfection was a major problem in patients admitted to the ICU-there was compelling evidence that the inflammatory response was the main driver of disease severity-empirical administration of antibiotics was widespread [2]. This was also advocated by international guidelines [3], based on extrapolation from other viral diseases e.g., influenza, while for coronavirus infections in the past, superinfection occurred in only $14 \%$ of patients during the total ICU stay [4]. When bacterial pneumonia

\footnotetext{
*Correspondence: Jan.DeWaele@UGent.be

${ }^{1}$ Department of Critical Care Medicine, Ghent University Hospital, C. Heymanslaan 10, 9000 Gent, Belgium
}

Full author information is available at the end of the article develops, this is typically later in the clinical course, presenting as late-onset ventilator-associated pneumonia [5]. A recent meta-analysis found that only $3.5 \%$ of all COVID19 patients present with co-infection, and 14\% develop infections at a later stage; in critically ill patients, an estimated $8 \%$ developed infections (including co-infection and secondary infection) [6]. Most of the data in this metaanalysis come from centers in China and it is not clear how this applies to other patient populations and settings.

Admittedly the situation was challenging. Patients were in the ICU and ventilated for much longer than usual, with an inherent risk of nosocomial infections. The diagnostic approach for bacterial infection was difficult, with the inflammatory response in COVID-19 mimicking the clinical construct of bacterial infection. Another factor was the potential risk of transmitting the virus by performing invasive diagnostic procedures. At the same time, it was more cumbersome to examine a patient as usual due to the obstacles of donning and doffing each time. The reluctance to disconnect ventilator circuits and sample the airways because of the aerosol generated in the procedure made fewer microbiological samples available. Supplementary Table 1 lists challenges encountered as well as solutions to improve antimicrobial use.

Furthermore, COVID-19 has led to a fundamental reorganization of hospitals and ICUs, and this new situation also impacted AMS efforts. Also, the care for the patients was changed in different ways, with non-ICU healthcare workers $(\mathrm{HCW})$ taking care of critically ill patients, capacity expanded to over $200 \%$ in many hospitals, and critically ill patients admitted to areas of the hospital that were not designed for this purpose. As a result, infection prevention was under duress, and there was even a risk of personal protective equipment becoming a vector for horizontal transmission. Finally, the increased workload for $\mathrm{HCW}$ also contributed to this.

\section{Springer}


So, what can we learn from this experience? Rational infection management remains of utmost importance. We list some recommendations for this in Supplementary Table 2. More research will be needed to assist in developing evidence based guidance (Supplementary Table 3). Surely new insights and treatments may continue to challenge ASPs. The use of immunomodulatory and potentially immunosuppressive drug such as corticosteroids or interleukin inhibitors may increase patient susceptibility for bacterial, viral or fungal superinfection, but for now there is no evidence to prophylactically treat patients with antimicrobials. For practical use, we propose a flow chart to guide empirical antibiotic therapy (Fig. 1). Also other aspects of AMS should not be forgotten e.g. appropriate dosing in situations such as acute kidney injury (AKI) or in case of renal replacement therapy (RRT) or extracorporeal membrane oxygenation (ECMO) use.

In summary, the use of antimicrobial drugs in the COVID-19 pandemic highlights the importance of upholding the AMS principles. Although it is challenging to apply the concepts used outside of pandemics, we need to reflect on how antimicrobial agents should be used. We have summarized a number of challenges in this respect, but for each of them, potential solutions are available. Rational infection management remains the goal.

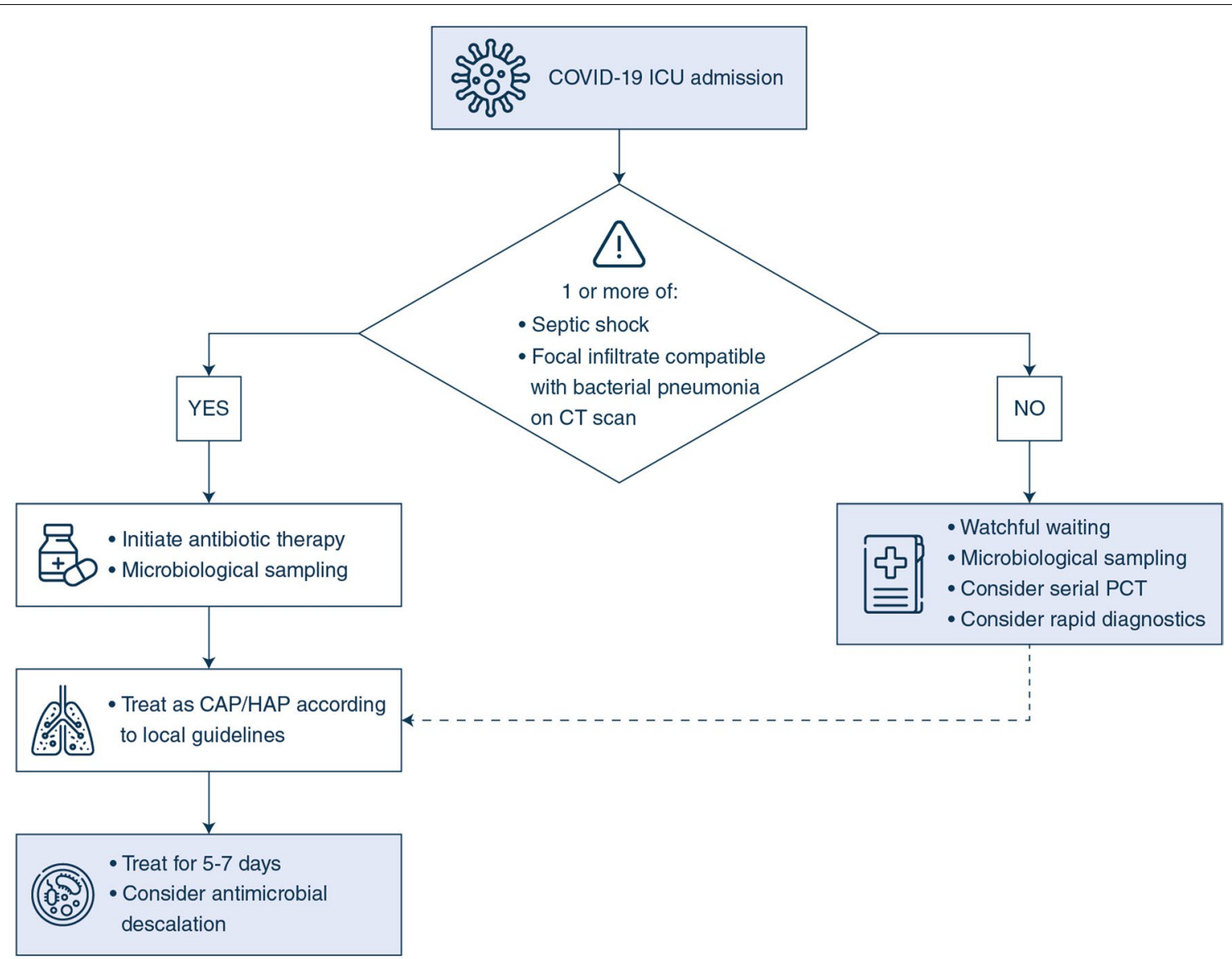

Fig. 1 Clinical algorithm for initiating antibiotics in patients admitted with COVID-19 to the ICU 


\section{Conflicts of interest}

JDW: grant from the Flanders Research Foundation (Senior Clinical Investigator Grant); consulted for Accelerate, Bayer Healthcare, Grifols, MSD, Pfizer (honoraria were paid to his institution). LD: none. MB: outside the submitted work, MB has participated in advisory boards and/or received speaker honoraria from Achaogen, Angelini, Astellas, Bayer, Basilea, BioMérieux, Cidara, Gilead, Menarini, MSD, Nabriva, Paratek, Pfizer, Roche, Melinta, Shionogi, Tetraphase, VenatoRx and Vifor and has received study grants from Angelini, Basilea, Astellas, Shionogi, Cidara, Melinta, Gilead, Pfizer and MSD.

\section{Electronic supplementary materia}

The online version of this article (https://doi.org/10.1007/s00134-020-06278-x) contains supplementary material, which is available to authorized users.

\section{Author details}

${ }^{1}$ Department of Critical Care Medicine, Ghent University Hospital, C. Heymanslaan 10, 9000 Gent, Belgium. ${ }^{2}$ Department of Intensive Care Medicine, University Medical Center Utrecht, Utrecht University, Utrecht, The Netherlands. ${ }^{3}$ Julius Center for Health Sciences and Primary Care, Utrecht, The Netherlands. ${ }^{4}$ Infectious Diseases Clinic, Department of Health Sciences, University of Genoa and Policlinico San Martino, Genoa, Italy.

\section{Funding}

None.

\section{Publisher's Note}

Springer Nature remains neutral with regard to jurisdictional claims in published maps and institutional affiliations.

Received: 5 August 2020 Accepted: 5 October 2020 Published online: 17 October 2020

\section{References}

1. Arabi YM, Murthy S, Webb S (2020) COVID-19: a novel coronavirus and a novel challenge for critical care. Intensive Care Med 46:833-836. https:// doi.org/10.1007/s00134-020-05955-1

2. Rawson TM, Moore LSP, Zhu N, Ranganathan N, Skolimowska K, Gilchrist M, Satta G, Cooke G, Holmes A (2020) Bacterial and fungal co-infection in individuals with coronavirus: a rapid review to support COVID-19 antimicrobial prescribing. Clin Infect Dis. https://doi.org/10.1093/cid/ciaa530

3. Alhazzani W, Møller MH, Arabi YM, Loeb M, Gong MN, Fan E, Oczkowski S, Levy MM, Derde L, Dzierba A, Du B, Aboodi M, Wunsch H, Cecconi M, Koh Y, Chertow DS, Maitland K, Alshamsi F, Belley-Cote E, Greco M, Laundy M, Morgan JS, Kesecioglu J, McGeer A, Mermel L, Mammen MJ, Alexander PE, Arrington A, Centofanti JE, Citerio G, Baw B, Memish ZA, Hammond N, Hayden FG, Evans L, Rhodes A (2020) Surviving sepsis campaign: guidelines on the management of critically ill adults with coronavirus disease 2019 (COVID-19). Intensive Care Med 46:854-887. https://doi. org/10.1007/s00134-020-06022-5

4. Lansbury L, Lim B, Baskaran V, Lim WS (2020) Co-infections in people with COVID-19: a systematic review and meta-analysis. J Infect. https://doi. org/10.1016/j.jinf.2020.05.046

5. Dudoignon E, Caméléna F, Deniau B, Habay A, Coutrot M, Ressaire Q, Plaud B, Berçot B, Dépret F (2020) Bacterial Pneumonia in COVID-19 critically ill patients: a case series. Clin Infect Dis. https://doi.org/10.1093/cid/ ciaa762

6. Langford BJ, So M, Raybardhan S, Leung V, Westwood D, MacFadden DR, Soucy J-PR, Daneman N (2020) Bacterial co-infection and secondary infection in patients with COVID-19: a living rapid review and metaanalysis. Clin Microbiol Infect. https://doi.org/10.1016/j.cmi.2020.07.016 